manufacture it. A car company may analyse past and current sales, customer behaviour and other data to supply dealerships with the most desirable car models. Factories want assurance that changing a machine tool will not affect the quality of their product.

Study general predictive models. Models need to be able to handle uncertainties such as degrading equipment or data errors from streaming failures or faulty sensors. A missing or erroneous data point could cause costly disruption to systems that produce one-of-akind products, such as medical implants.

Connect factories and control processes. Current software for controlling production processes and resource planning, such as the widely used SAP package, will face challenges in a more dynamic and open manufacturing environment that straddles many different producers. Most software is designed for use by a single corporation. Research is needed to ensure that such systems can operate together through open interfaces and universal standards. New programmes suited to cloud computing may be required, and could take inspiration from complexity in the natural world - such as the genome, bird flocks and the human immune system. Real-world experimentation is also needed, through prototypes, test beds and virtual and augmented reality.

\section{ENERGY AND HEALTH CARE}

Accomplishing all this requires intellectual effort, money and better collaboration between industry, academia and government. In the past five years, several regional initiatives for smart manufacturing have been set up. But their goals are mainly directed by industry, and the more general aspects of data and modelling receive little attention.

One such initiative is the US-based Smart Manufacturing Leadership Coalition, launched in 2012. Companies pay a fee to join and members determine the research agenda and goals - one being an openaccess platform for collecting plant-level data and systems.

Germany's Plattform Industrie 4.0 (part of the government's High-Tech Strategy 2020) promotes the computerization of its industrial base, for example using machinery that anticipates failures and triggers maintenance processes autonomously. The European Union is investing $€ 7$ billion (US\$7.6 billion) by 2020 in Factories of the Future, a publicprivate partnership to develop a blueprint for smart manufacturing. Japan and China have similar programmes.

I suggest that energy and health care should be the first foci for deep collaboration, because they have the greatest societal impact. For example, the life cycles and manufacture of wind turbines need rethinking.
Their components - gear boxes, generators, blades, towers and kilometres of cables - are built in conventional ways from materials (mainly metals) sourced from and shipped around the globe. After 20 years of use, turbines may be scrapped. Smart processes should be designed to make and decommission them more sustainably. New technologies such as additive manufacturing should be explored. The smart manufacturing initiatives mentioned here should work with global initiatives such as the Breakthrough Energy Coalition to promote renewable energy sources, and the US Cancer Moonshot initiative that seeks clinical and technological advances in cancer treatment.

Lessons can be learned from precedents set in the $1990 \mathrm{~s}^{2}$. Progress in intelligent manufacturing was limited by several factors, including the inability to see the value of large-scale international col-

laboration, lack of governmental endorsement, and different management styles of cor-

porations across the globe. In 1995, Japan launched its Intelligent Manufacturing System to connect major national manufacturing industries and universities with global partners. The US government did not endorse the collaborations. Meanwhile, a consortium of US companies established the Next Generation Manufacturing Systems programme, which linked with Japan's iniative and others in Asia and Europe. Trust, will, conviction and policies are now needed for similar endeavours to succeed.

\section{NEW PLATFORMS}

Three practical steps need to be taken to plug knowledge gaps and enable smart manufacturing.

Establish networks to define problems. Consortia of private corporations, foundations, academia and governmental entities should set up online forums where practitioners and researchers can discuss, develop and publish specifications of emerging industrial problems. Many corporations have internal sites for soliciting ideas. Ways to integrate services and manufacturing processes would be worthy topics to start with. Different modes of operations and financial support ranging from crowdsourcing to licences and fees for service should be considered.

Develop platforms for modelling, sharing and innovation. As the world becomes more complex, a gap is opening up between those who understand industrial needs and those with the skills to model and solve problems. Online or physical spaces should be provided by consortia involving industry, academia and government, in which experts and practitioners can interact to develop technical solutions and models. These platforms might mirror 'maker spaces' or the innovation hubs promoted by the US National Science Foundation and companies that do research, such as SRI International, Procter \& Gamble and Google.

Parties must overcome issues of trust and reticence to reveal information. Collaborative structures should support transparency and openness as well as diverse ideas and cultures. It is essential that small and medium enterprises are involved. The consortia should develop schemes to allow modellers to access private data.

Enact smart manufacturing policies. Although industry will drive much of the shift to smart manufacturing because it makes business sense, governments should fill gaps or support areas too risky for private investment. For example, a 2016 report $^{3}$ by the Information \& Technology Innovation Foundation, a policy think tank in Washington DC, called on the US Congress to expand federal resources for training and to help small- and medium-sized businesses to adopt smart manufacturing technologies. Incentives might include an investment tax credit for updating machinery and equipment.

By acting as one to deliver the tools, industry, government and academia can make the next industrial revolution a reality.

Andrew Kusiak is professor of mechanical and industrial engineering at the University of Iowa, Iowa City, Iowa, USA.

e-mail:andrew-kusiak@uiowa.edu

1. Berggren, M., Nilsson, D. \& Robinson, N. D. Nature Mater. 6, 3-5 (2007)

2. Kusiak, A. Intelligent Manufacturing Systems (Prentice Hall, 1990).

3. Ezell, S. J. A Policymaker's Guide to Smart Manufacturing (Information \& Technology Innovation Foundation, 2016).

\section{CLARIFICATION}

It has emerged that the unpublished 1950 s essay referred to in the Comment 'Winston Churchill's essay on alien life found' (M. Livio Nature 542, 289-291; 2017) and held at the US National Churchill Museum in Fulton, Missouri, is one of several versions. The Fulton holding, 'Are we alone in the universe?', is a light reworking of a $1939 \mathrm{draft}$, 'Are we alone in space?', held at the Churchill Archives Centre, Cambridge, UK. Part of that draft - minus passages on the nature of life and on Jupiter was published as 'Are There Men on the Moon?' in The Sunday Dispatch on 8 March 1942, and in The Collected Essays of Sir Winston Churchill (Library of Imperial History, 1975). 